\title{
Stromal Cells Provide Signals Different from Cytokines for STAT5 Activation in Hematopoietic Cells
}

\author{
Asako K. Sato, Nobuaki Yanai, Tadashi Okubo, Kazuhiro J. Mori, and Masuo Obinata* \\ Department of Cell Biology, Institute of Development, Aging and Cancer, Tohoku University, Seiryo-machi, \\ Aoba-ku, Sendai 980-8575, and Faculty of Science, Niigata University Japan
}

\begin{abstract}
After detachment from the stromal cells, hematopoietic stem cells are thought to differentiate to the cytokine-dependent stages where their growth and differentiation are promoted by these cytokines. To examine the stromal regulation of hematopoietic stem cells, we previously established a primitive hematopoietic stem-like cell line, THS119, whose growth was dependent on the bone marrow stromal cell line, TBR59, and from which IL-3- (THS119/IL-3) or IL-7- (THS119/IL-7) dependent cell lines were then generated. Using these cell lines, we examined the difference in signals mediated by the stromal cells and cytokines.

The cytokine-dependent cell lines (THS119/IL-3 and THS119/IL-7) showed induction of STAT5 phosphorylation and target genes for STAT5 such as CIS, pim-1, p21 and bcl-xL upon addition of IL-3 or IL-7. IL-3 or IL-7 also induced STAT5 phosphorylation and STAT5 target genes of the stromal cell-dependent cell line, THS119, in the absence of stromal cells at levels similar to the cytokine-dependent cell lines. However, quite interestingly, TBR59 stromal cells could not induce STAT5 phosphorylation of THS119 cells, although they did induce STAT5 target genes in THS119 cells. In addition, the mRNAs for STAT5 target genes in THS119 cells on the stromal cells seemed to be more stable than those in the cytokine-dependent cell lines. Expression of the antiapoptotic genes bcl-2 and bcl-xL was higher in the stromal cell-dependent cell line than in the cytokine-dependent cell lines. These results suggested that stromal cells and cytokines may provide different signals for growth and differentiation of the hematopoietic cells.
\end{abstract}

Key words: $\quad$ stromal cell/IL-3/IL-7/hematopoietic stem cell

Studies on long-term bone marrow culture have shown that hematopoietic stem cells can be maintained for a long-time in culture on the stromal cell layers of bone marrow, in which the self-renewal and differentiation of the hematopoietic stem cells and their progenitors are regulated by stromal cell-stem cell communication via factors secreted from the stromal cells, extracellular matrices and adhesion molecules (Dexter et al., 1977; Itoh et al., 1989, 1996; Kodama et al., 1984; Mauch et al., 1980).

To study how the stem cells are regulated by the stromal cells, we have established many stromal cell lines from bone marrow of temperature-sensitive (ts) SV40 large T-

\footnotetext{
* To whom correspondence should be addressed: Department of Cell Biology, Institute of Development, Aging and Cancer, Tohoku University, Seiryo-machi, Aoba-ku, Sendai 980-8575, Japan.

Tel: +81-22-717-8483, Fax: +81-22-717-8488

E-mail: mobinata@idac.tohoku.ac.jp

Abbreviations: STAT, transducer and activators of transcription; IL, interleukin; CIS, cytokine-inducible SH2-containing protein; OSM, oncostatin $\mathrm{M}$.
}

antigen gene transgenic mice (Kameoka et al., 1995) and reported that cobblestone areas containing myeloid and B-lymphoid progenitors were formed from the sorted stem cells depending on a bone marrow stromal cell line, TBR59 (Iguchi et al., 1997; Koguma et al., 1998; Okuyama et al., 1995). Using this stromal cell line as feeder layer, a novel stromal cell-dependent primitive hematopoietic cell line, THS119, was established from the sorted $\mathrm{Lin}^{-} / \mathrm{Sca}-1^{+}$cells of bone marrow of ts SV40 large T-antigen gene transgenic mice after long-term passages (Yanai et al., 1999).

THS119 cells expressed c-Kit and Sca-1, but did not express any surface markers (Gr-1, TER119, Mac-1, CD3, or B220) of differentiated hematopoietic cells, and showed multiple expression of lineage-restricted hematopoietic transcription factors, indicating that they retained immature phenotypes of the fractionated hematopoietic stem cells after immortalization. We examined whether known cytokines could be replaced from the stromal cells for maintenance of THS119 cells, but none of the cytokines supported 
maintenance when IL-3, IL-6, IL-7, G-CSF, GM-CSF, MCSF, Epo, or SCF was added to THS119 cells without stromal cells. However, when these cytokines were continuously added to the cocultures of THS119 cells with TBR59 cells for 2 months, the cells were able to grow in the presence of either IL-3 or IL-7 without TBR59 stromal cells and, finally, IL-3- (THS119/IL-3) or IL-7- (THS119/IL-7) dependent cell lines were established (Yanai et al., 1999).

It is thought that after detachment from the stromal cells, hematopoietic stem cells differentiate to the cytokine-dependent stages where their growth and differentiation are promoted by these cytokines. In the present study, we examined the different responses to cytokines and stromal cells shown by the stromal cell-dependent THS119 cell line and the IL-3- or IL-7-dependent cell lines.

Since signal transducers and activators of transcription (STATs) are known to be indispensable for intracellular signaling after stimulation with cytokines, growth factors and hormones (Darnell, 1997), we examined the induction of STAT5 phosphorylation and STAT5 target genes. The results suggested that the stromal cells and cytokines may provide different signals for growth and differentiation of hematopoietic stem cells.

\section{Materials and Methods}

\section{Culture of THS119 cells and the cytokine-dependent cell lines}

Culture of THS119 cells and TBR59 stromal cells was performed as reported previously (Yanai et al., 1999). Throughout the experiments, E-RDF medium (Kyokuto Pharmaceutical Co., Ltd., Tokyo, Japan) supplemented with 5\% FBS, $10 \mu \mathrm{g} / \mathrm{ml}$ transferrin, 5 $\mu \mathrm{g} / \mathrm{ml}$ insulin, $4.3 \mathrm{ng} / \mathrm{ml}$ sodium selenite, $1.53 \mu \mathrm{g} / \mathrm{ml}$ ethanolamine, and $100 \mu \mathrm{M}$ 2-mercaptoethanol (2-ME) was used as a basic medium. For the cytokine-dependent cell lines, THS119/IL-3 was maintained in the presence of $2 \mathrm{ng} / \mathrm{ml}$ of IL-3 and THS119/IL-7 was maintained in the presence of $2 \mathrm{ng} / \mathrm{ml}$ of IL-7. Recombinant murine IL-3 was generously provided by Kirin Co. (Tokyo), and recombinant IL-7 was purchased from Genzyme (Cambridge, MA).

For analysis of growth of THS119 cells on TBR59 cells, conflu- ent cell layers of TBR59 stromal cells were first formed in 6-well plates, and $2 \times 10^{5}$ of THS119 cells were inoculated onto each well and cultured at $33^{\circ} \mathrm{C}$. Cell numbers were counted after recovering THS 119 cells by collagenase treatment.

\section{Detection of phosphorylation of STAT5 protein by Western blotting}

To determine their cytokine response, THS119 cells were removed from the coculture with TBR59 stromal cells, washed twice, and transferred to the culture medium. Similarly, the cytokine-dependent cell lines maintained in the presence of IL-3 or IL-7 were washed twice and transferred to the culture medium without cytokines. The transferred cells were cultured for $4 \mathrm{hr}$ and then either IL-3 $(10 \mathrm{ng} / \mathrm{ml})$ or IL-7 $(5 \mathrm{ng} / \mathrm{ml})$ was added to the culture and incubated for $30 \mathrm{~min}$ to detect phosphorylation of STAT5 protein.

Cells were homogenized in lysis buffer containing $50 \mathrm{mM}$ Tris- $\mathrm{HCl} \mathrm{pH}$ 8.0, 0.5\% NP40, 1 mM EDTA, $150 \mathrm{mM} \mathrm{NaCl}, 10 \%$ glycerol, $1 \mathrm{mM}$ sodium vanadate, $50 \mathrm{mM}$ sodium fluoride, 10 $\mathrm{mM}$ sodium pyrophosphate, and proteinase inhibitor cocktail (Boehringer Mannheim, Germany). The extracts were clarified by centrifugation at $15,000 \mathrm{rpm}$ at $4^{\circ} \mathrm{C}$ for $15 \mathrm{~min}$. The samples were resolved in SDS-PAGE and proteins were detected by immunoblotting with anti STAT5 (C-17) (Santa Cruz Biotechnology, Santa Cruz, CA) (Matsumoto et al., 1999). Slowly migrating bands were assigned as phosphorylated STAT5 proteins (Beadling et al., 1996).

\section{Detection of mRNA by RT-PCR}

Total RNA was isolated by Isogen (Wako Pure Chemicals, Ltd., Tokyo) according to the manufacturer's protocol. Five $\mu \mathrm{g}$ total RNA was denatured for $10 \mathrm{~min}$ at $70^{\circ} \mathrm{C}$ and reverse transcribed for $50 \mathrm{~min}$ at $42^{\circ} \mathrm{C}$ in a final volume of $20 \mu \mathrm{l} \mathrm{PCR}$ buffer containing 6.6 units $/ \mathrm{ml}$ SuperScript II RT, $0.5 \mathrm{mM}$ dNTP, $25 \mathrm{ng} / \mu \mathrm{g}$ Oligo(dT) primer, $1.25 \mathrm{mM} \mathrm{MgCl}_{2}, 5 \mathrm{mM}$ DTT (SuperScript ${ }^{\mathrm{TM}}$ Preamplification System, GIBCO BRL). The RT reactions were terminated by heating for $15 \mathrm{~min}$ at $70^{\circ} \mathrm{C}$. RT products were amplified by PCR amplification using $0.25 \mathrm{U} / \mathrm{ml}$ taq polymerase (AmpliTaq Gold, Perkin Elmer) with the gene specific primers for different gene probes (Table I) in a final volume of $10 \mu \mathrm{l}$. Cycling conditions consisted of a melting step at $94^{\circ} \mathrm{C}(30 \mathrm{sec})$, an annealing step at an appropriate annealing temperature $(30 \mathrm{sec})$ and an extension step

Table I. OLIGONUCLEOTIDE PRIMERS USED IN THIS STUDY

\begin{tabular}{llll}
\hline Gene & \multicolumn{1}{c}{ 5' primer } & \multicolumn{1}{c}{ 3' primer } & \multicolumn{1}{c}{ Reference } \\
\hline CIS & CTGGAGCTGCCCGGGCCAGCC & CAAGCCTGACCACATCTGGG & Bjorbaek et al., 1999 \\
OSM & CGGCACAATATCCTCGGCATAAGG & TGCTCCTGGAAGGTCTGATTTTGC & Lischke et al., 1998 \\
pim-1 & CACCGACACCCTGGAGGT & GCTACTTGCTGGATCCCG & Nosaka et al., 1999 \\
p21 & ATGTCCAATCCTGGTGATGTCCG & CTTCAGGGTTTCTCTTGCAG & Wu et al., 1996 \\
bcl-xL & ATGTCTCAGAGCAACCGG & TCACTTCCGACTGAAGAGTG & Nosaka et al., 1999 \\
bcl-2 & TCGCTACCGTCGTGACTTC & AAACAGAGGTCGCATGCTG & \\
bax & ATGCGTCCACCAAGAAGCTGAG & CCCCAGTTGAAGTTGCCATCAG & Tomayko et al., 1998 \\
GAPDH & CTTCACCACCATGGAGAAGG & TGAAGTCGCAGGAGACAACC & \\
\hline
\end{tabular}


at $72^{\circ} \mathrm{C}(90 \mathrm{sec})$. The number of cycles was determined to be that which showed a linear trajectory before they reached the maximum plateau. Each amplification product was electrophoresed on $2 \%$ agarose gel and visualized by staining with ethidium bromide.

\section{Results}

\section{Growth properties of stromal cell-dependent and cytokine-dependent cell lines}

THS119 cells were grown depending on TBR59 stromal cells, and IL-7 or IL-3 did not support their growth in the absence of stromal cells, although TBR59 cells produced significant levels of IL-7 (Koguma et al., 1998; Yanai et al., 1999). The IL-3-dependent cell line (THS119/IL-3) and IL7-dependent cell line (THS119/IL-7) which were generated after 2 months of coculture with TBR59 in the presence of these cytokines, showed cytokine-dependent growth (Yanai et al., 1999).

Growth properties of these 3 cell lines were examined as shown in Fig. 1. Parental THS119 cells grew well on TBR59 stromal cells and IL-7 or IL-3 stimulated them only slightly on the stromal cells. The IL-3-dependent cell line, THS119/IL-3, could not grow in the absence of cytokines, and IL-3 strongly supported its growth, while IL-7 weakly supported it. IL-7 strongly supported growth of the IL-7-dependent cell line, THS119/IL-7, while IL-3 did not stimulate its growth, but seemed to prevent apoptosis since its cell number was maintained. In both cytokine-dependent cell lines, simultaneous addition of IL-7 and IL-3 caused significantly higher growth stimulation than did single addition.

Both cytokine-dependent cell lines showed a very slow growth rate on the stromal cells in the absence of cytokines, but cytokines stimulated the growth of both lines when cultured on TBR59 stromal cells at levels similar to those in the absence of TBR59 cells. These results indicated that growth of THS 119 cells was stromal cell-dependent, whereas THS119/IL-3 and THS119/IL-7 cell lines were cytokinedependent.

\section{Phosphorylation of STAT5 in 3 cell lines}

It is well known that STATs are transcription factors indispensable for intracellular signaling after stimulation with cytokines, and that they form homo- or heterodimers upon phosphorylation of tyrosine residues, usually by Janus kinase (JAKs). Dimerized STAT proteins immediately enter the nucleus and bind to the specific DNA sequences in the
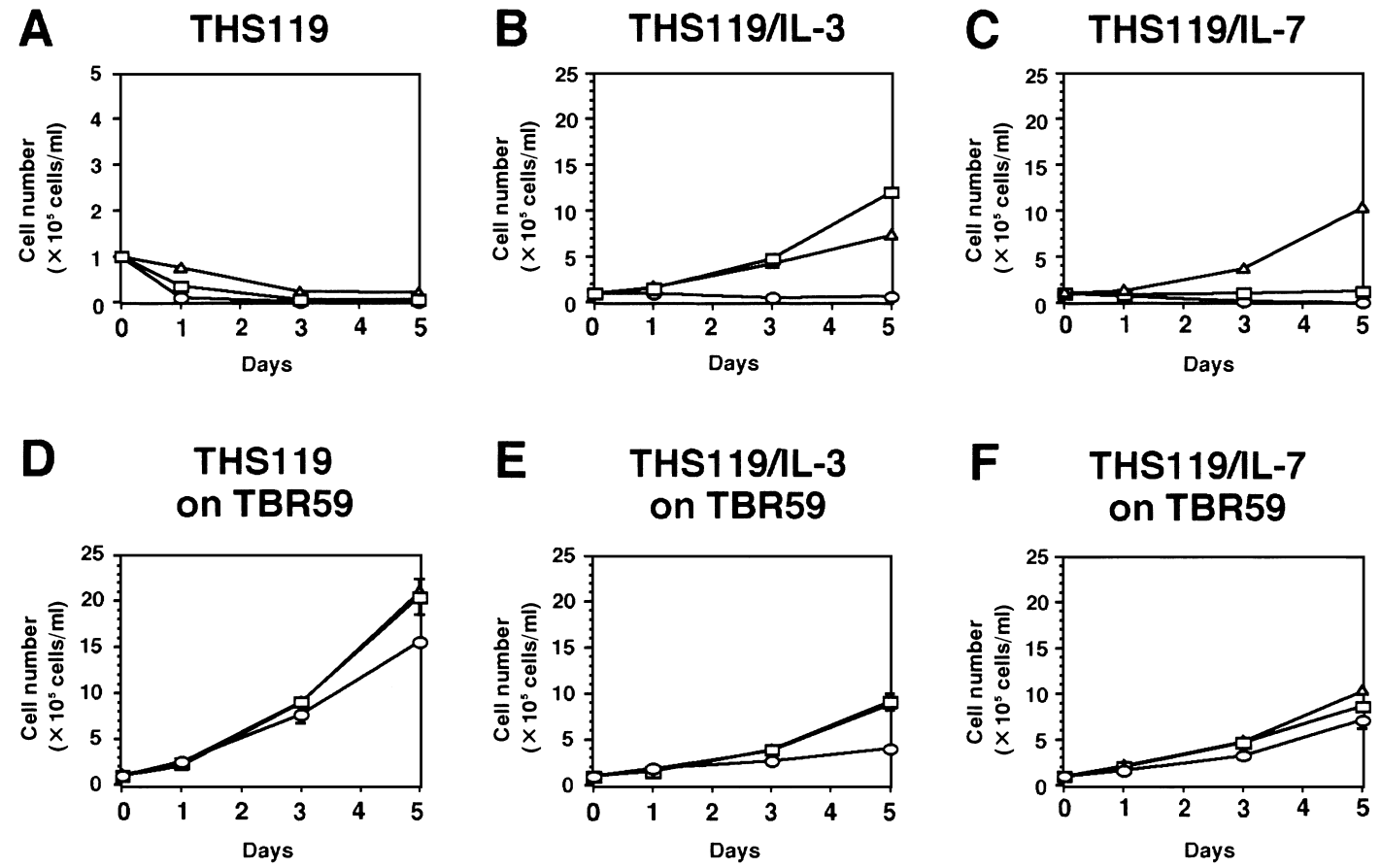

Fig. 1. Stromal cell-dependent and cytokine-dependent growth of THS119, THS119/IL-3, THS119/IL-7 cell lines. For culture of the cell lines on TBR59 cells, confluent cell layers of TBR59 stromal cells were first formed in 6 -well plates, $2 \times 10^{5}$ of the cells were inoculated onto each well and the cultures were incubated at $33^{\circ} \mathrm{C}$. In the absence of stromal cells, the cells were cultured in the absence of cytokines, or in the presence of $10 \mathrm{ng} / \mathrm{ml}$ of IL-3 or $5 \mathrm{ng} / \mathrm{ml}$ of IL7, respectively. After culture on the stromal cells, the hematopoietic cells were removed from the stromal cells by collagenase treatment and cell numbers were counted. A, B and C: The cells were cultured without TBR59 stromal cell layers, but in the absence of cytokines (O) or in the presence of either IL-3 $(\square)$ or IL-7 ( $\triangle$ ). D, E and F: The cells were cultured on the TBR59 stromal cell layers in the absence of cytokines $(\bigcirc)$ or in the presence of either IL-3 ( $\square$ ) or IL-7 $(\triangle)$. 
promoter regions of various genes, resulting in gene activation or repression. Since upon addition of IL-3 or IL-7, signals mediated by their receptors were known to induce phosphorylation of STAT5 proteins (Brown et al., 1999; Mui et al., 1995, 1996; Rosenthal et al., 1997; van der Plas et al., 1996), phosphorylation of STAT5 was examined as shown in Fig. 2. IL-3 or IL-7 induced strong phosphorylation of STAT5 in both THS119/IL-3 and THS 119/IL-7 and also induced its phosphorylation in THS119 cells at levels similar to THS119/IL-3 or THS119/IL-7, when these cytokines were added to the culture in the absence of stromal cells. Interestingly, THS119 cells on TBR59 stromal cells, however, showed only barely detectable levels of STAT5 phosphorylation. These results suggested that the support of THS119 cells by the stromal cells may be mediated by signals other than the activation of STAT5, although THS119 cells have the responsibility for the cytokine-dependent STAT5 activation pathways.

\section{Induction of STAT5 target genes in 3 cell lines by cytokines and stromal cells}

To examine the induction of STAT5 target genes after STAT5 phosphorylation, RNAs were isolated from the 3 cell lines that had been cultured under different conditions and the induction of these mRNAs was monitored by RTPCR method. CIS is one of the STAT5 target genes and was isolated as the immediate response gene for IL-3 (Yoshimura et al., 1995). In both cytokine-dependent cell lines, IL-3 or IL-7 induced CIS mRNA, but IL-3 showed a stronger effect. Interestingly, THS119 grown on the TBR59 stromal cells maintained significantly high levels of CIS mRNA, although STAT5 phosphorylation was barely detectable and IL-3 or IL-7 induced it more strongly (Fig. 3). When THS119 cells were transferred to the culture in the absence of TBR59 cells and IL-3 or IL-7 was added to this culture, CIS mRNA was rapidly (within $1 \mathrm{hr}$ ) induced at levels sim- ilar to the cytokine-dependent cell lines, although neither cytokine promoted growth of THS119 cells in the absence of TBR59. These results suggested that the stromal cell-dependent cell line, THS119, retained the signaling pathways responding to cytokines, similar to the cytokine-dependent cell lines.

In addition to CIS mRNA, we examined expression of oncostatin M, pim-1, bcl-xL, and p21 that are known to be the target genes for STAT5 (Noasaka et al., 1999). The results showed that an essentially similar expression of pim-1, bcl-xL, and p21 was induced to that of CIS mRNA. Oncostatin $M$ is known to be induced by IL-3 through STAT5 (Yoshimura et al., 1996), however, to our surprise, oncostatin $\mathrm{M}$ was constitutively expressed even in the absence of cytokines among these cell lines.

mRNAs for STAT5 target genes except oncostatin M were rapidly reduced (within $4 \mathrm{hr}$ ) when the cytokine-dependent cell lines were cultured in the absence of cytokines, whereas they were stably expressed in THS119 cells even without stromal cells. These results suggested that the mRNA for STAT5 target genes (CIS, bcl-xL, pim-1, p21) were more stable in THS119 cells after detachment from the stromal cells than those in the cytokine-dependent cell lines after withdrawal of cytokines.

\section{Expression of bcl-2 and bax genes}

Maintenance of hematopoietic cells may require antiapoptotic activity. Since stromal cells and cytokines induced antiapoptotic gene bcl-xL which was regulated as a target for STAT5 in these cell lines, we investigated the expression of another antiapoptotic gene bcl-2 and the proapoptotic gene bax (Gibson et al., 1996; Oltvai et al., 1993). While bax was expressed constitutively, bcl-2 gene was highly expressed in THS119 on the stromal cells, whereas neither IL-3 nor IL-7 induced its mRNA at significant levels in either of the cytokine-dependent cell lines.

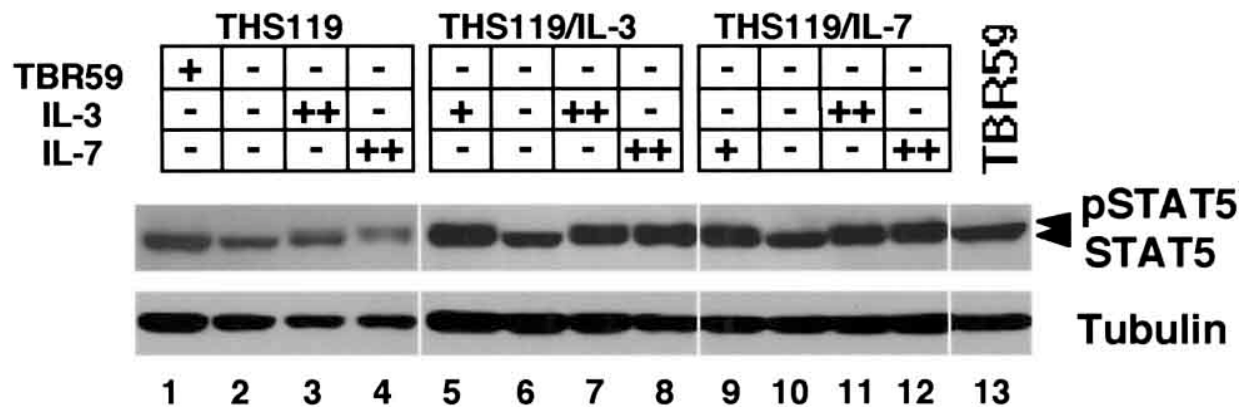

Fig. 2. STAT5 phosphorylation. STAT5 phosphorylation was determined as described in Materials and Methods. In lanes 1, 5, and 9, samples were obtained from cells continuously cultured in the presence of TBR59 stromal cells for THS119, in the presence of IL-3 for THS119/IL-3, and in the presence of IL-7 for THS119/IL-7, respectively. In lanes 2, 6, and 10, samples were obtained from cells cultured in the absence of growth stimuli for 4 hr (depleted culture). In lanes 3,7, and 11, IL-3 was added to the depleted culture and incubated for $30 \mathrm{~min}$. In lanes 4, 8 and 12, IL-7 was added to the depleted culture and incubated for $30 \mathrm{~min}$. The samples ( $25 \mu \mathrm{g}$ of protein/lane) were resolved in SDS-6\% PAGE and proteins were detected by immunoblotting with anti STAT5 (C-17). Slowly migrating bands (upper arrow: pSTAT5) showed phosphorylated STAT5 proteins. Tubulin antibody was used for monitoring the amount of protein loaded in the samples. 


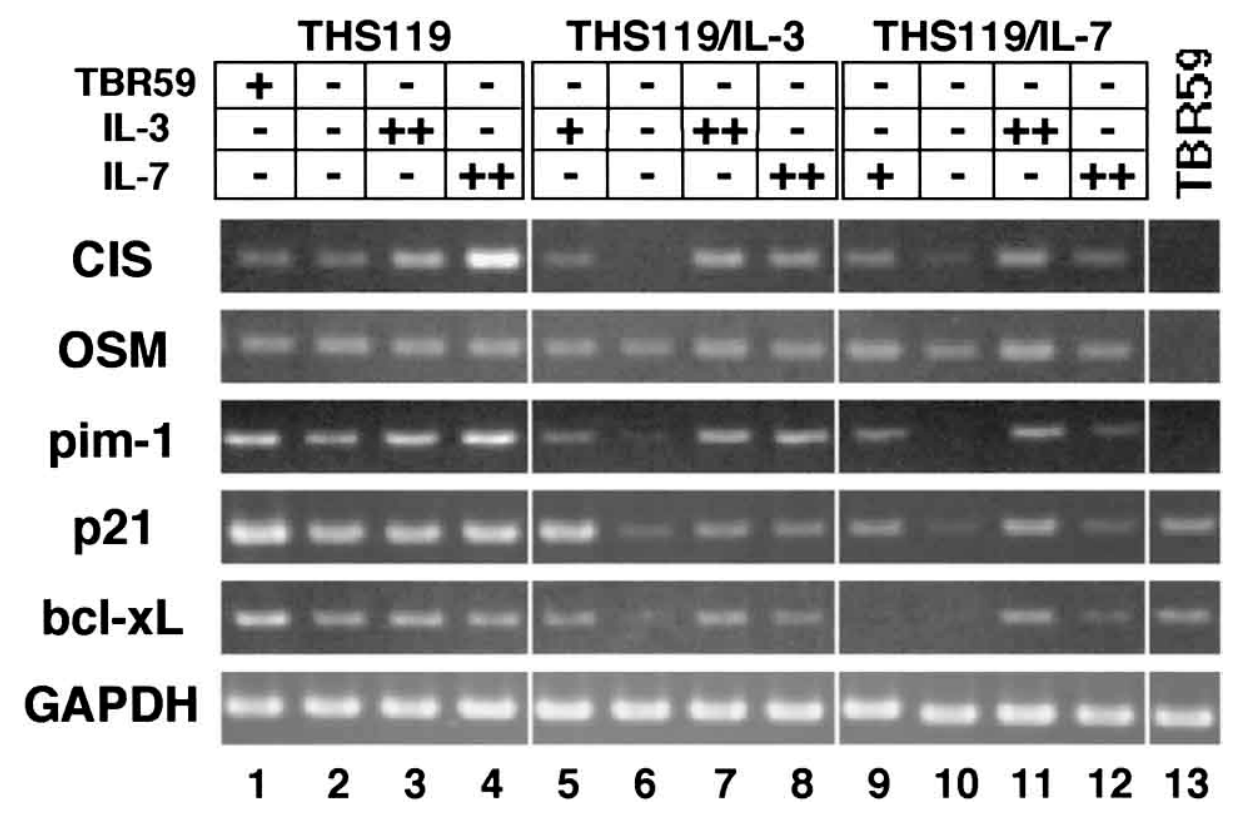

Fig. 3. Analysis of expression of genes downstream of STAT5. Levels of expression were monitored by RT-PCR as described in Materials and Methods. RNA samples in each lane are the same as in the Fig. 2, but the samples were taken from the cells incubated for 1 hr after addition of cytokines.

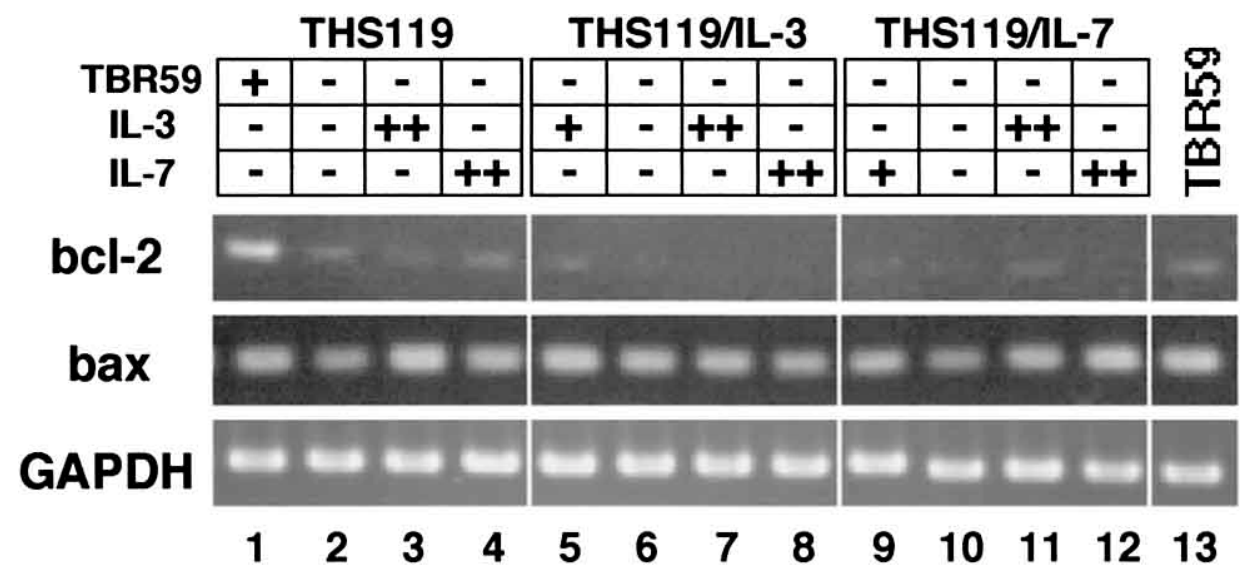

Fig. 4. Expression of bcl-2 and bax genes. RNA samples were obtained from the culture of THS119 in the presence (+) or absence (-) of TBR59 stromal cells, THS119/IL-3 in the presence (+) or absence (-) of IL-3, and THS119/IL-7 in the presence (+) or absence (-) of IL-7, respectively.

\section{Discussion}

Within the bone marrow, self-renewal and differentiation of the hematopoietic stem cells may be regulated by the contact with the stromal cell layers (Dexter et al., 1977; Itoh et al., 1989, 1996; Kodama et al.,1984; Mauch et al., 1980; Spooncer and Dexter, 1997). After detachment from the stromal cells, hematopoietic stem cells might differentiate to the growth factor-dependent stages and its growth and differentiation may be promoted by these cytokines (Okubo et al., 2000). To understand this process, we established stromal cell-dependent hematopoietic stem cell lines by using one of the bone marrow stromal cell lines, TBR59. We succeeded in establishing the THS119 cell line, a novel TBR59 stromal cell-dependent primitive hematopoietic cell line from the bone marrow stem cells sorted as $\mathrm{Lin}-/ \mathrm{Sca}-1^{+}$ cells (Yanai et al., 1999). Growth of THS119 cells was TBR59 stromal cell-dependent, and therefore they induced apoptosis gradually even in the presence of cytokines after detachment from the stromal cells. However, IL-3 or IL-7dependent cell lines could be generated from THS119 cells after prolonged culture with cytokines on the stromal cells.

We compared the properties of the stromal cell-dependent THS119 cell line and the two cytokine-dependent cell lines, THS119/IL-3 and THS119/IL-7, to determine whether the stem cells acquire their response to cytokines after de- 
tachment from the stromal cells.

Although THS119 and the two cytokine-dependent cell lines expressed mRNAs for the IL-3 or IL-7 receptors to similar extents (Yanai et al., 1999), the growth of THS119 was highest on TBR59 stromal cells while IL-3 and IL-7 stimulated its growth only slightly, indicating that the stromal signals may be preferable for the maintenance of THS119 cells. On the contrary, IL-3 promoted growth of THS119/IL-3 and IL-7 promoted growth of THS119/IL-7, but both these cell lines showed only slight growth on TBR59 stromal cells, indicating that cytokines may be preferable for the growth signals of these cells.

We examined STAT5 phosphorylation since signals mediated by IL-3 or IL-7 receptors were known to induce phosphorylation of STAT5 proteins (Mui et al., 1995, 1996; Rosenthal et al., 1997). In both cytokine-dependent cell lines, IL-3 and IL-7 induced STAT5 phosphorylation to a similar extent, although both showed rather preferential growth stimulation to THS119/IL-3 or THS119/IL-7. In addition, CIS, bcl-xL, pim-1, and p21 as target genes for STAT5 were induced at levels corresponding to those of STAT5 phosphorylation in both cytokine-dependent cell lines. Although IL-3 did not stimulate growth of THS119/ IL-7, it seemed to protect apoptosis; thus induction of bcl$\mathrm{xL}$ may partly be involved in the antiapoptotic effect of IL3 . Thus, both cytokine-dependent cell lines may have the same signaling pathways through STAT5 proteins, but IL-3 or IL-7 may preferentially use the upstream signals in combination with some other costimulatory signals.

In THS119, a stromal cell dependent cell line, STAT5 phosphorylation was induced by IL-3 or IL-7 in the absence of stromal cells at levels similar to those in the cytokine-dependent cell lines; thus THS119 cells may have the same signaling pathways via STAT5 proteins as do the cytokinedependent cell lines. However, STAT5 phosphorylation in THS119 cells was barely detectable when cells were cultured on TBR59 stromal cells, even though a significant level of IL-7 was produced in TBR59 cells as reported elsewhere (Koguma et al., 1998). Therefore, TBR59 stromal cells may use the dominant signals to support THS119 cells in processes other than STAT5 phosphorylation. In contrast to the absence of STAT5 activation, THS119 cells expressed CIS, bcl-xL, pim-1, p21 and oncostatin M, target genes for STAT5 proteins. It is likely that phosphorylation of the STAT family protein other than STAT5 and/or other signaling pathways mediated by the stimulus of TBR59 stromal cells may be required for the induction of expression of CIS, bcl-xL, pim-1, p21 and oncostatin M.

It is noted that mRNAs for STAT5 target genes (CIS, bcl$\mathrm{xL}$, pim-1, p21) were more stable in THS119 cells after detachment from the stromal cells than those in the cytokinedependent cell lines after withdrawal of cytokines. These suggested that the stromal signals may be more persistent while the cytokine signals may be transient. Such signaling pathways may be important to determining the supporting activity of the hematopoietic stem cells by the stromal cells in a bone marrow hematopoietic microenvironment.

On proapoptotic and antiapoptotic genes, stromal cells induced bcl-2 gene more strongly than cytokines, and bcl-xL mRNA persisted after detachment from the stromal cells, whereas bax, a proapoptotic gene, was expressed constitutively in all cell lines to a similar extent. These results suggest that stromal cells may provide stronger survival signals for the hematopoietic cells than cytokines. On regulation of bcl-2 gene, it was reported that insulin-like growth factor-I (IGF-I) induces a cAMP-response element (CRE) sitecontaining bcl-2 promoter through a novel signaling pathway involving mitogen-activated protein kinase kinase 6/ p38beta mitogen-activated protein kinase/MAP kinase-activated protein kinase-3 (MAPK kinase 6/p38beta MAPK/ MAPKAP-K3)/ cAMP-response element-binding protein (CREB) (Pugazhenthi et al., 1999). Furthermore, regulation of bcl-2 expression by IGF-I was shown to involve a signaling cascade mediated by PI3-kinase/PDK1/Akt/ CREB (Pugazhenthi et al., 2000). It would be interesting to determine whether stromal signals that induce bcl-2 gene expression are mediated by IGF-I secreted from the stromal cells.

Finally, we demonstrated that oncostatin $\mathrm{M}$ was constitutively expressed in all 3 cell lines even in the absence of stromal cells or cytokines, while it was isolated as a rapidly inducible gene which responded to IL-3 and was shown to be a target gene for STAT5. It is possible that THS119 could produce cytokines that stimulated its growth, but we favor the view that oncostatin $\mathrm{M}$ and/or cytokines may regulate the supporting ability of the stromal cells, because we demonstrated that supporting ability of the bone marrow stromal cells was stimulated by exogenously added oncostatin M (Yanai et al., in preparation). Since THS119 cells were originated from Dexter's long-term bone marrow culture where the hematopoietic cells were maintained by a mixture of stromal cells, the continuous expression of oncostatin $\mathrm{M}$ by the hematopoietic cells may stimulate the supporting ability of the stromal cells during the establishment of cell lines, and hence may facilitate establishment of THS119 cell line as a stromal cell-dependent hematopoietic stem cell line. This mutual regulation between stromal cells and hematopoietic cells may also be important in the hematopoietic microenvironment.

Acknowledgments. This work was supported by a Grant-in-Aid from the Ministry of Education, Science, Sports and Culture of Japan and NEDO funds from the Japanese government.

\section{References}

Beadling, C., Ng, J., Babbage, J.W., and Cantrell, D.A. 1996. Interleukin2 activation of STAT5 requires the convergent action of tyrosine kinases and a serine/threonine kinase pathway distinct from the Raf1/ERK2 MAP kinase pathway. EMBO J., 15: 1902-1913.

Bjorbaek, C., Elmquist, J.K., El-Haschimi, K., Kelly, J., Ahima, R.S., 
Hileman, S., and Flier, J.S. 1999. Activation of SOCS-3 messenger ribonucleic acid in the hypothalamus by ciliary neurotrophic factor. Endocrinology, 140: 2035-2043.

Brown, M.P., Nosaka, T., Tripp, R.A., Brooks, J., van Deursen, J.M., Brenner, M.K., Doherty, P.C., and Ihle, J.N. 1999. Reconstitution of early lymphoid proliferation and immune function in Jak3-deficient mice by interleukin-3. Blood, 94: 1906-1914.

Darnell, J.E., Jr. 1997. STATs and gene regulation. Science, 277: 16301635.

Dexter, T.M., Allen, T.D., and Lajtha, L.G. 1977. Conditions controlling the proliferation of haemopoietic stem cells in vitro. J. Cell Physiol., 91: 335-344.

Gibson, L.F., Piktel, D., Narayanan, R., Nunez, G., and Landreth, K.S. 1996. Stromal cells regulate bcl-2 and bax expression in pro-B cells. Exp. Hematol., 24: 628-637.

Iguchi, A., Okuyama, R., Koguma, M., Obinata, M., and Yanai, N. 1997. Selective stimulation of granulopoiesis in vitro by established bone marrow stromal cells. Cell Struct. Funct., 22: 357-364.

Itoh, K., Tezuka, H., Sakoda, H., Konno, M., Nagata, K., Uchiyama, T., Uchino, H., and Mori, K.J. 1989. Reproducible establishment of hemopoietic supportive stromal cell lines from murine bone marrow. Exp. Hematol., 17: 145-153.

Itoh, K., Friel, J., Kluge, N., Kina, T., Kondo-Takaori, A., Kawamata, S., Uchiyama, T., and Ostertag, W. 1996. A novel hematopoietic multilineage clone, Myl-D-7, is stromal cell-dependent and supported by an alternative mechanism(s) independent of stem cell factor/c-kit interaction. Blood, 87: 3218-3228.

Kameoka, J., Yanai, N., and Obinata, M. 1995. Bone marrow stromal cells selectively stimulate the rapid expansion of lineage-restricted myeloid progenitors. J. Cell Physiol., 164: 55-64.

Kodama, H., Sudo, H., Koyama, H., Kasai, S., and Yamamoto, S. 1984. In vitro hemopoiesis within a microenvironment created by MC3T3-G2/ PA6 preadipocytes. J. Cell Physiol., 118: 233-240.

Koguma, M., Matsuda, K., Okuyama, R., Yanai, N., and Obinata, M. 1998. Selective proliferation of lymphoid cells from lineage-c-Kit+ Sca-1+ cells by a clonal bone marrow stromal cell line. Exp. Hematol., 26: 280 287.

Lischke, A., Moriggl, R., Brandlein, S., Berchtold, S., Kammer, W., Sebald, W., Groner, B., Liu, X., Hennighausen, L., and Friedrich, K. 1998. The interleukin-4 receptor activates STAT5 by a mechanism that relies upon common gamma-chain. J. Biol. Chem., 273: 31222-31229.

Matsumoto, A., Seki, Y., Kubo, M., Ohtsuka, S., Suzuki, A., Hayashi, I., Tsuji, K., Nakahata, T., Okabe, M., Yamada, S., and Yoshimura, A. 1999. Suppression of STAT5 functions in liver, mammary glands, and T cells in cytokine-inducible $\mathrm{SH} 2$-containing protein 1 transgenic mice. Mol. Cell Biol., 19: 6396-6407.

Mauch, P., Greenberger, J.S., Botnick, L., Hannon, E., and Hellman, S. 1980. Evidence for structured variation in self-renewal capacity within long-term bone marrow cultures. Proc. Natl. Acad. Sci. USA, 77: 29272930.

Mui, A.L., Wakao, H., O'Farrell, A.M., Harada, N., and Miyajima, A. 1995. Interleukin-3, granulocyte-macrophage colony stimulating factor and interleukin-5 transduce signals through two STAT5 homologs. EMBO J., 14: 1166-1175.

Mui, A.L., Wakao, H., Kinoshita, T., Kitamura, T., and Miyajima, A. 1996. Suppression of interleukin-3-induced gene expression by a C-terminal truncated Stat5: role of Stat5 in proliferation. EMBO J., 15: 2425-2433.

Nosaka, T., Kawashima, T., Misawa, K., Ikuta, K., Mui, A.L., and Kitamura, T. 1999. STAT5 as a molecular regulator of proliferation, differentiation and apoptosis in hematopoietic cells. EMBO J., 18: 4754 4765 .

Okubo, T., Yanai, N., and Obinata, M. 2000. Self-renewal and differentiation of a novel bipotent myeloid progenitor clone in the stroma-dependent culture. Exp. Hematol., 28: 651-659.

Okuyama, R., Koguma, M., Yanai, N., and Obinata, M. 1995. Bone marrow stromal cells induce myeloid and lymphoid development of the sorted hematopoietic stem cells in vitro. Blood, 86: 2590-2597.

Oltvai, Z.N., Milliman, C.L., and Korsmeyer, S.J. 1993. Bcl-2 heterodimerizes in vivo with a conserved homolog, Bax, that accelerates programmed cell death. Cell, 74: 609-619.

Pugazhenthi, S., Miller, E., Sable, C., Young, P., Heidenreich, K.A., Boxer, L.M., and Reusch, J.E. 1999. Insulin-like growth factor-I induces bcl-2 promoter through the transcription factor cAMP-response element-binding protein. J. Biol. Chem., 274: 27529-27535.

Pugazhenthi, S., Nesterova, A., Sable, C., Heidenreich, K.A., Boxer, L.M., Heasley, L.E., and Reusch, J.E. 2000. Akt/protein kinase B up-regulates $\mathrm{Bcl}-2$ expression through cAMP- response element-binding protein. $J$. Biol. Chem., 275: 10761-10766.

Rosenthal, L.A., Winestock, K.D., and Finbloom, D.S. 1997. IL-2 and IL7 induce heterodimerization of STAT5 isoforms in human peripheral blood T lymphoblasts. Cell Immunol., 181: 172-181.

Spooncer, E. and Dexter, T.M. 1997. Culturing primitive hemopoietic cells. Long-term mouse marrow cultures and the establishment of factordependent (FDCP-Mix) hemopoietic cell lines. Methods Mol. Biol., 75 : 209-219.

Tomayko, M.M. and Cancro, M.P. 1998. Long-lived B cells are distinguished by elevated expression of A1. J. Immunol., 160: 107-111.

van der Plas, D.C., Smiers, F., Pouwels, K., Hoefsloot, L.H., Lowenberg, B., and Touw, I.P. 1996. Interleukin-7 signaling in human B cell precursor acute lymphoblastic leukemia cells and murine BAF3 cells involves activation of STAT1 and STAT5 mediated via the interleukin-7 receptor alpha chain. Leukemia, 10: 1317-1325.

Wu, H., Wade, M., Krall, L., Grisham, J., Xiong, Y., and Van Dyke, T. 1996. Targeted in vivo expression of the cyclin-dependent kinase inhibitor p21 halts hepatocyte cell-cycle progression, postnatal liver development and regeneration. Genes Dev., 10: 245-260.

Yanai, N., Matsui, N., Matsuda, K.I., Furusawa, T., Okubo, T., Nakazawa, T., Ishibashi, K., Nawa, K., and Obinata, M. 1999. A novel stromal celldependent hematopoietic cell line established from temperature-sensitive SV40 T-antigen transgenic mice. Exp. Hematol., 27: 1087-1096.

Yoshimura, A., Ohkubo, T., Kiguchi, T., Jenkins, N.A., Gilbert, D.J., Copeland, N.G., Hara, T., and Miyajima, A. 1995. A novel cytokineinducible gene CIS encodes an $\mathrm{SH} 2$-containing protein that binds to tyrosine-phosphorylated interleukin 3 and erythropoietin receptors. EMBO J., 14: 2816-2826.

Yoshimura, A., Ichihara, M., Kinjyo, I., Moriyama, M., Copeland, N.G., Gilbert, D.J., Jenkins, N.A., Hara, T., and Miyajima, A. 1996. Mouse oncostatin M: an immediate early gene induced by multiple cytokines through the JAK-STAT5 pathway. EMBO J., 15: 1055-1063.

(Received for publication, March 1, 2001

and in revised form, April 6, 2001) 